\title{
Spatial dynamics and agglomeration forces in the external EU periphery
}

\author{
Dimitris Kallioras $^{1} \cdot$ Vassilis Monastiriotis $^{2}$ (D) \\ George Petrakos ${ }^{1}$
}

Received: 15 March 2015 / Accepted: 21 November 2016 / Published online: 2 December 2016 (C) The Author(s) 2016. This article is published with open access at Springerlink.com

\begin{abstract}
The countries belonging to the European Neighborhood Policy (ENP) of the EU are characterized by significant socioeconomic transformations and-more recently-by disconcerting instances of social and political turmoil. This comes to add to social and economic pressures applied to these countries under their process of market liberalization and economic integration, instigated at least in part by the very ENP process. In those conditions, questions of spatial cohesion and thus of regional convergence and divergence become increasingly salient, as the elimination of (social and) spatial imbalances is both a precondition for the legitimacy and successful implementation of the reforms aiming at market liberalization and economic integration and a core objective of such reforms. In this paper, we examine the spatial dynamics of population growth in the ENP countries prior to the recent destabilization in the region, using two complementary approaches — an analysis of the impact of agglomeration on growth and an analysis of club formation in population concentrations (convergencedivergence). We find that, on the whole, the ENPCs South space was characterized in
\end{abstract}

Electronic supplementary material The online version of this article (doi:10.1007/s00168-016-0798-x) contains supplementary material, which is available to authorized users.

$\triangle$ Vassilis Monastiriotis

V.Monastiriotis@1se.ac.uk

Dimitris Kallioras

dkallior@uth.gr

George Petrakos

petrakos@uth.gr

1 Department of Planning and Regional Development, University of Thessaly, Pedion Areos, PO 38334 Volos, Greece

2 European Institute, London School of Economics and Political Science, Cowdray House, Houghton Street, London WC2A 2AE, UK 
recent years by evidence of regional convergence in the sense that population concentrations were becoming more diffused across regions; while the ENPCs East exhibited stronger and more consistent evidence of regional divergence (increased concentration of population). These findings suggest that agglomeration and cumulative causation forces are more strongly in operation in the more advanced, at least in terms of EU relations, countries of the ENP East, where also the "pull" factor of the EU economy is stronger.

JEL Classification $\mathrm{C} 13 \cdot \mathrm{C} 14 \cdot \mathrm{R} 11 \cdot \mathrm{R} 12$

\section{Introduction}

The recent European Union (EU) enlargements brought the borders of the EU to a set of countries in the East with historically less intensive economic relations and little experience with democratic capitalism. These countries have been part of the (former) Soviet Union and are characterized by lower development levels and significant institutional and structural weaknesses. At the same time, in the Southern and the Eastern rim of the Mediterranean Sea, the EU is faced with countries that are facing their own challenges with regard to economic and democratic transition and which are historically linked to individual EU countries through their colonial past. Both bordering areas, in the EU East and the EU South, have been gaining significance as they include emerging economies, energy suppliers, or, simply, a large neighboring market, which is crucial for the EU economy. More importantly, perhaps, they have been gaining significance for security reasons, including in relation to illegal migration and the control of international terrorism and, more recently, the refugee crisis. In response to these, the EU launched, in 2004, the European Neighborhood Policy (ENP), a unified policy framework toward its neighboring countries (the ENPCs), laying in the external EU periphery, aiming at strengthening prosperity, stability and security around its geo-political borders (EC 2004, 2010, 2011, inter alia). The policy covers six countries of the "eastern" neighborhood (Armenia, Azerbaijan, Belarus, Georgia, Moldova and Ukraine - the ENPCs East) and ten countries of the "southern" neighborhood (Algeria, Egypt, Israel, Jordan, Lebanon, Libya, Morocco, Occupied Palestinian Territory (Palestine), Syria and Tunisia - the ENPCs South). Recent developments in the region (i.e., Ukrainian crisis, Libya and Syria wars) saw the revision of the ENP framework with a shift of focus to security and societal issues (human trafficking, anti-radicalization, youth unemployment) aiming not only at economic stabilization but also at addressing social and political destabilization (Monastiriotis and Borrell 2013; EC 2015). This is especially in response to the sociopolitical turmoil that has engulfed some of these countries, especially after the short period of optimism following the so-called Arab Spring, and which has resulted in significant and sometimes extreme population movements both inside (Ukraine) and outside (Syria) their borders.

Partly motivated by these significant social and demographic changes, in this paper we take a step back and seek to examine the dynamics of population growth within each of the ENP countries prior to recent turmoil. Borrowing from the urban economics literature, but applied here at the regional level (partly due to data limitations), 
we look at one particular influence on population change, namely the role of agglomeration. We examine specifically whether sub-national population change responds positively or negatively to agglomeration (measured as population density), i.e., in ways that reinforce or instead equalize population concentrations across space. This question has a relevance which goes beyond the demographic interest per se. In the absence of good quality (or, sometimes, any) sub-national level income data, examining processes of concentration and de-concentration of population can also shed light on questions concerning economic convergence/divergence more generally. Although, admittedly, interest in spatial patterns of disparity is generally associated to variables measuring income and welfare, the analysis of the spatial dynamics of population concentration is important both in itself and in the sense of understanding wider economic processes (Duranton and Puga 2014). Indeed, scholars both in the urban economics (Fujita 1988; Heslsey and Strange 1990; Glaeser 1999; Duranton and Puga 2001) and the growth economics tradition (Lucas 1988; Glaeser et al. 1995) have well-recognized that studying population growth offers a window through which to study the process of economic growth as the latter is systematically related to population growth through the trade-off between agglomeration economies and urban (i.e., commuting, housing, land use, environmental, inter alia) costs. This is especially so in the context of the ENP space, in particular, given that productivity levels, capital deepening and levels of technology in these countries are still low and thus economic growth is still very much of the extensive (increase in inputs, including labor) than the intensive form (increase in the productivity of each input and in total factor productivity). Moreover, given that the vast majority of these countries are still at low levels of economic development, spatial productivity differentials are predominantly along the lines of urban-rural (core-periphery) dichotomy (Harris and Todaro 1970; Galor and Weil 2000; Hansen and Prescott 2002; Lucas 2004; Henderson and Wang 2005), and thus very much related to patterns of population agglomeration (urbanization). In these conditions, measures of spatial disparity in population concentration act as a lower bound indicator of spatial disparities in economic activity and wealth. Thus, by examining how agglomeration influences population growth across space-irrespective of whether this is instigated by migration or natural movements-we also obtain some insight into how agglomeration influences economic growth across regions in these countries.

Irrespective, however, of the question as to how well spatial inequalities in population growth reflect disparities in economic indicators (e.g., regional GDP per capita), examining the dynamics of the former-and whether they reflect cumulative or equilibrating tendencies-is of acute analytical and policy interest in itself. If patterns of population growth are found to be cumulative across space, this could be taken as a signal of a wider spatial disequilibrium in these countries, representing spatial inequalities in economic opportunities more generally. The latter would in turn raise concerns about social and economic cohesion in these countries and ultimately about the support to-and legitimacy of - processes of market liberalization and economic integration, including those instigated directly by the EU's policy in the region under the ENP framework. This is especially important because, as the literature has shown in relation to the experience of previous EU association waves, spatial imbalances are often accentuated by processes of deeper association and integration with the EU 
(Neven 1995; Quah 1996; Rodriguez-Pose and Fratesi 2004; Barrios and Strobl 2009; Petrakos et al. 2011; Monastiriotis 2014; Monastiriotis et al. 2016, inter alia). As a corollary, accentuated spatial disparities (both in incomes and in perceived economic opportunities), and the legitimacy questions that they may raise, can act as an impediment to the ability of the EU to stimulate, and pursue, effective democratization in its neighborhood. Thus, either as a possible side-effect of integration or as a precondition for its success, the extent of regional disparities and imbalances in the associated countries matters.

Nevertheless, explained to a large extent by the absence of suitable data and especially data that would be comparable across countries, the literature has so far only offered very limited insights into these questions of spatial disparities and their dynamics in the ENP space. Among the handful of exceptions, the paper by Peridy et al. (2013) stands out as perhaps the most comprehensive study to date to examine questions of regional convergence for a group of ENPCs. Specifically, the authors use regionalized GDP data from the Yale University GEcon3.3 dataset project to study spatial dependence as well as conditional and unconditional convergence at the sub-national level for a sub-set of MENA (Middle East and North Africa) countries. Although this is a welcome contribution to what is, largely, an unexplored topic, their reliance on artificially constructed regional units on the basis of "1-degree latitude by 1-degree longitude terrestrial grid cells" makes their empirical findings somewhat less relevant for understanding the actual special-economic dynamics underpinning the growth process of these countries' actual regional economies. Besides this, a limited number of studies have examined patterns of regional disparities for a select few number of countries for which better-quality data exist (e.g., Demchuck and Zelenyuk 2009; Kokko and Kravtsova 2012; Kallioras and Tsiapa 2015 for Ukraine; Lipshitz and Raveh 1998; Portnov and Erell 2004; Beenstock and Felsenstein 2008 for Israel; Petrakos et al. 2016 for Azerbaijan, Armenia, Georgia, Israel and Ukraine).

In this context, the analysis presented in this paper makes, we believe, an important contribution to our knowledge and understanding of spatial processes in the ENP region. To perform our analysis, we take two complementary steps. First, we specify a simple equation which makes population growth a function of population density. We treat this as an insight model for the relationship between agglomeration and growth, a relationship that has been examined widely and under a variety of settings in the spatial economics literature (see, inter alia, Cheshire and Magrini 2000; Brülhart and Sbergami 2009; Boschma et al. 2012). We note that although the intuition of the model derives from the literature of the economics of agglomeration (Marshalian externalities, knowledge spillovers, etc.—see Glaeseret al. 1991; Coombes 2000) its form is equivalent to a simple (unconditional) convergence model specified in terms of population densities. Geared with the empirical evidence collected from this analysis and the similarity in form to the convergence hypothesis, we then move on to perform a more detailed analysis of club convergence, using the methodology developed by Chatterji (1992) and Chatterji and Dewhurst (1996) which examines the temporal dynamics of each region's distance from a national frontier.

In both cases of the empirical analysis, we find evidence of diffusion of agglomerations, or of convergence, only in a minority of countries and regions. On the whole, the ENPCs South space is characterized by evidence of diffusion of agglomerations 
(convergence), while the ENPCs East exhibits stronger and more consistent evidence of regional concentration (divergence). Our results suggest that agglomeration and cumulative causation forces are more strongly in operation in the more advanced, at least in terms of EU relations, countries of the ENP East, where also the "pull" factor of the EU economy is stronger. In contrast, in parts of the ENPCs South we find that agglomeration forces play a limited role and thus that centripetal tendencies of divergence are scarcer and weaker. These findings, besides their academic interest more generally, provide significant implications as regards EU policy in the ENPCs-an issue that we touch upon in the concluding section. Before that, in the next section we present some basic descriptive information on our sample of ENPCs regions and the details of our empirical approach. Sections 3 and 4 present, respectively, our empirical analysis on the impact of agglomeration on population growth and on the possibility for the emergence of regional convergence clubs at the sub-national level. As noted above, the last section concludes with some implications for policy.

\section{Descriptive patterns and empirical approach}

In our empirical analysis, we use data derived from the SEARCH Database ${ }^{1}$ (SEARCH 2013), which includes population data at the regional level (which is comparable to EU NUTS II spatial level) for the full sample of ENP countries. ${ }^{2}$ The period covered by our data is broadly the period from the late 1990s to the early 2010s. It should be noted that our pooled sample pools together a cross section of regions across countries, for which data on average annual population growth rates and initial year population densities cover slightly different periods (e.g., 2000-2011 in Armenia, 1998-2008 in Algeria). Although this may seem as a limitation, we make no claim that these periods are strictly homogenous across countries (e.g., in terms of their political, demographic and economic development). In fact, this would not hold true even in the case that our data were covering exactly the same start and end years for each of the countries under analysis. Instead, we treat this broad period as a phase which is broadly homogenous in terms of the development of relations of these countries with the EU, i.e., a phase starting after the establishment of the Barcelona Process in the south and the wave of the post-communist transitions in the east and ending at the time of the Arab Spring in the south and before the recent turmoil that has hit parts of the EU neighborhood in both the east and the south (i.e., Ukraine crisis, Syrian War). Table 1 presents the list of countries and periods of our data coverage.

It should come as no surprise that the distribution of population, and of population densities, in the ENPCs is highly skewed. As is typical with countries of lower levels of development (Berry 1961; El-Shakhs 1972; Wheaton and Shishido 1981; Parr 1985; Petrakos and Brada 1989; Ades and Glaeser 1995; Henderson 2002), a pattern of metropolitan dominance seems to characterize much of the ENPCs economic space.

\footnotetext{
1 SEARCH database compiled within the framework of the homonymous FP7 Research Project. See http:// www.ub.edu/searchproject/ for further details.

2 Palestine is not included in the analysis due to the lack of data. Also, Libya is not included in the analysis since we have data for only one year (i.e., 2006).
} 
Table 1 Population data description Sources: SEARCH (2013)/authors' elaboration a Abkhazia is not included

${ }^{b}$ Judea and Samaria area is not included

\begin{tabular}{llc}
\hline Country & Period covered & Number of regions \\
\hline Armenia & $2000-2011$ & 11 \\
Azerbaijan & $2000-2012$ & 11 \\
Belarus $_{\text {Georgia }}{ }^{\mathrm{a}}$ & $2001-2012$ & 7 \\
Moldova $_{\text {Ukraine }}^{2002-2012}$ & 11 \\
Algeria & $2005-2012$ & 5 \\
Egypt & $2000-2012$ & 27 \\
Israel & $1998-2008$ & 48 \\
Jordan & $1996-2012$ & 27 \\
Lebanon & $2000-2010$ & 6 \\
Morocco & $2000-2011$ & 11 \\
Syria & $2004-2007$ & 6 \\
Tunisia & $2003-2009$ & 16 \\
\hline
\end{tabular}

Indeed, in most of the ENPCs, the capital regions exhibit the highest population density figures. Nevertheless, this does not apply to all ENPCs. In parts of the ENPCs South sub-group (particularly, Egypt, Israel, Jordan and Morocco), the capital regions are not the ones exhibiting the highest population density figures. Still, even in these cases, population density in the main metropolitan region of each country is many times higher than the corresponding average and minimum figures in each country's other regions. Indeed, for many non-metropolitan regions a situation of desolation emerges at least in some parts of the ENPCs - especially in countries such as Georgia, Algeria, Egypt, Jordan, Morocco and Tunisia, where there are regions with extremely low population density figures.

These patterns are summarized in Table 2, which depicts some basic population density data for the administrative regions of the ENPCs. Specifically, Table 2 shows the minimum, average and maximum population density figures for each ENPC, at the regional level. As can be seen, average population densities vary significantly across the ENPCs, ranging from over $3300 \mathrm{inh} . / \mathrm{sq}$. km in Lebanon to less than 200 inhabitants per square kilometer in Azerbaijan. Within-country disparities are even more pronounced-not so much in the ENPCs East, where max-to-min ratio ranges between 15 (in Moldova) and 200 (in Armenia and Belarus), as in the ENPCs South, where max-to-min ratios take extreme values as high as 20,000 (in Algeria). ${ }^{3}$

Although such extreme disparities are to an extent to be expected, given the physical geography of the countries concerned ${ }^{4}$, they also raise interesting questions about the

\footnotetext{
3 This holds even though the main metropolitan regions in the ENPCs East exhibit (among) the highest population (density) growth rate(s), while, correspondingly, this is not exactly the case in the ENPCs South (cf. Tables A1.1-A.1.14 in the supplemental data online).

4 The physical geography of the ENPCs poses a caveat for our analysis that we have not been able to remedy. Specifically, it is possible that population in regions that include large sections of desert may
} 
Table 2 Population density data by country Sources: SEARCH (2013)/authors' elaboration

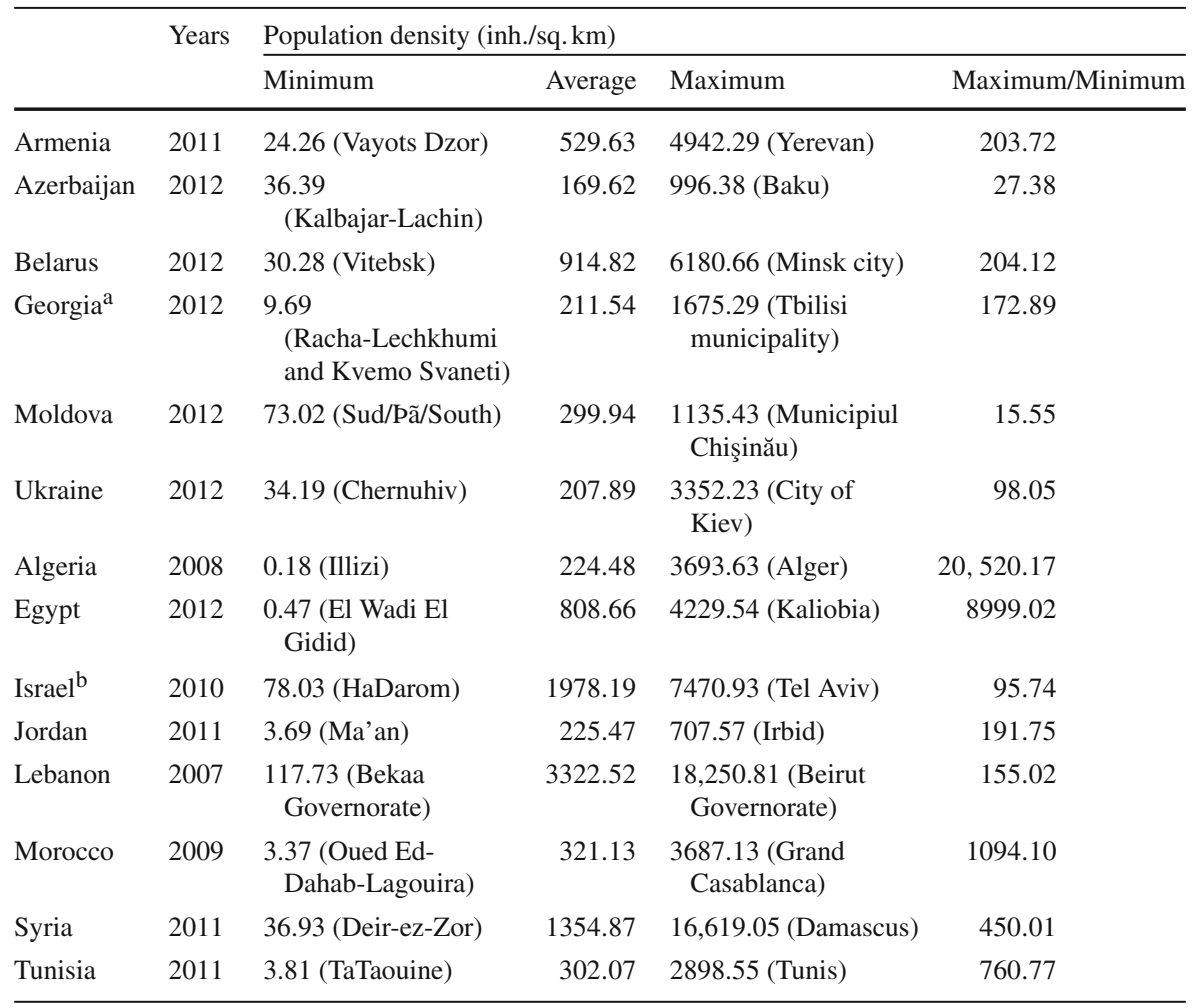

a Abkhazia is not included

$\mathrm{b}$ Judea and Samaria area is not included

\section{Footnote 4 continued}

be much more densely concentrated (in cities) than our measurement may imply. A similar problem would emerge if the regions of our analysis included a heterogeneous number of large cities: In this case, it is possible that population density at the regional level could appear higher in multi-city regions with cities of lower agglomeration (population density), thus biasing our measurement of agglomeration at the regional level. In the absence of accurate city-level population data, our approach for both possible biases was to check on a country-by-country basis and examine (a) to what extent desert regions included cities with densities comparable to those of non-desert regions (b) to what extent the regions of study had a heterogeneous number of large cities. Our exploratory analysis assured us that the bias introduced by our approach to measure population density at the region, than city, level was not particularly sizeable. Still the possibility of a bias remains. In this sense, the results presented in our analysis should be treated with caution as they are likely to present upper-bound estimates of the true extent of convergence/divergence in population densities. In any case, however, the bias concerns the extent rather than the direction of the identified effects. 
role of equilibrating (centrifugal) or cumulative (centripetal) forces and of agglomeration as a "pull" factor for population growth, in particular. To examine these, we perform two sets of analysis. We start with a simple analysis of the impact of agglomeration on population growth. Various strands of the literature have examined empirically this relationship, while a large theoretical literature also exists, following within the traditions of new economic geography and urban / spatial economics, which provide analytical support to this relationship. ${ }^{5}$ Empirical studies of the role of agglomeration on regional growth typically specify agglomeration on the basis of measures of density (Crescenzi et al. 2007; Dall and Schmidt 2015): Population density is central in this, often combined with other measures capturing different aspects of agglomeration, such as product variety and diversity (Boschma et al. 2012), spatial concentration of industrial activity (Brülhart and Sbergami 2009), concentration of human capital and entrepreneurship (Braunerhjelm and Borgman 2004), R\&D and economic potential (Cheshire and Magrini 2000) and others. In our analysis, we follow this literature and specify a simple regional growth equation where population growth is a function of agglomeration (measured by population density). Specifically,

$$
\dot{p}_{r, t}=\alpha+\beta A_{r, t-1}
$$

where $\dot{p}_{r, t}$ is population growth in region $r$ in year $t ; A_{r, t-1}$ measures population density ( $A=P / L$, where $L$ is a region's fixed area) in region $r$ in the period $t-1$; and $\alpha$ and $\beta$ are model parameters. It needs to be noted that, as $L$ is fixed over time, Eq. (1) is directly analogous (fully equivalent) empirically to a simple unconditional convergence equation specified in terms of population densities. Specifically,

$$
\begin{aligned}
\dot{p}_{r, t} & =\ln (P)_{r, t}-\ln (P)_{r, t-1}-\ln (L)_{r}+\ln (L)_{r} \\
& =\ln \left(\frac{P}{L}\right)_{r, t}-\ln \left(\frac{P}{L}\right)_{r, t-1}=\dot{A}_{r, t}=\alpha+\beta A_{r, t-1}
\end{aligned}
$$

In this sense, the estimate of $\beta$ in Eq. (1) can be discussed in terms of a convergence/divergence process: A negative $\beta$ suggests that population densities converge over time, so that relatively sparsely populated / low agglomeration regions catch-up to the more urbanized / higher agglomeration ones; a positive $\beta$ suggests that population densities diverge over time. To put it differently, a positive $\beta$ shows that agglomeration contributes positively to population growth, and thus that high agglomeration regions become disproportionately more dense (high agglomeration) over time (implying

\footnotetext{
5 See Baldwin and Martin (2004) for a detailed exposition of this thretical tradition. See also Sveikauskas (1975) and Beeson (1987) for earlier treatments of the same issue.
} 
regional divergence in population densities); a negative $\beta$ shows that agglomerations tend to subside over time and thus that regional population sizes converge. ${ }^{6,7}$

Following this analysis, in a second stage we delve deeper into the patterns of convergence and divergence in the ENPCs sub-groups by examining the possibility for the emergence of regional convergence clubs within each of the countries of our analysis. Broadly speaking, the notion of club convergence implies convergence to a common level only for (regional) economies that are both identical in their structural characteristics and similar in their initial conditions (see Quah 1993). In other words, convergence within each club allows for aggregate divergence or for divergence across clubs. In our empirical analysis of club convergence, we follow the approach proposed by Chatterji (1992) and Chatterji and Dewhurst (1996). This requires the identification of a lead economy (i.e., an economy that exhibits the highest value as regards the variable of population density, in particular), relating the gap (i.e., the difference between the population density level of the lead economy and the population density level of each of the economies under consideration, including the leading one) at one date with the corresponding gap at an earlier date, including further powers of those earlier levels. Particularly, the investigation for the emergence of regional convergence clubs is based on the econometric estimation of the equation:

$$
G_{r}^{F}=\sum_{k=1}^{K} \gamma_{k}\left(G_{r}^{B}\right)^{k}
$$

where $B$ denotes the base (initial) year of estimation, $F$ denotes the final year of estimation, $r$ denotes region, $G$ denotes the gap (in logarithmic terms), $\gamma(1,2, \ldots, K)$ is the coefficient of $G$, and $k(1,2, \ldots, K)$ are the powers of $G$. Allowing in this way higher powers of the "initial gap" variable allows us to identify groups of regions that belong to different "convergence clubs". This is done in relation to a benchmark linear function of the form $G^{F}=G^{B}$. The intersections between this benchmark function and the function estimated from the convergence clubs analysis point out the initial gap levels that correspond to equal final gap levels (i.e., there is neither convergence nor divergence).

\footnotetext{
6 The constancy of L means also that Eq. (1) is analogous empirically to a simple unconditional convergence equation specified in terms of population growth - this time with a space-varying convergence coefficient. Specifically, substituting $A=P / L$ into Eq. (1) gives. Interpreting this relation as a convergence equation implies that, for $<0$ regional populations convergence to a common steady-state, albeit at different paces, with the pace of convergence being uniquely influenced by each region's land area. This is equivalent to a standard convergence equation with region-specific slope coefficients (rates of convergence), of the form. It is obvious that the two equations are identical for. It follows that, empirically, estimating a population convergence equation can give us an estimate of the impact of population density on population growth (assuming that land areas are known). Analytically, however, our estimating relation (Eq. 1) attributes a role to agglomeration (density) which is not found in the convergence equation.

7 Of course, one cannot entirely exclude the possibility that the negative $\beta$ coefficient may depict unsynchronized phases of demographic change among different type of regions that are associated with a different spatial timing in the acceleration of population growth. We thank an anonymous Referee for this point.
} 


\section{Agglomeration and (population) growth}

As a starting point for our analysis of the impact of agglomeration on regional growth, we examine the relationship depicted by Eq. (1) at a macroregional (supra-national) level, first across the entire ENPCs macroregion and then separately for the ENPCs East and the ENPCs South sub-groups. We do so both in a simple OLS setting, pooling all regions and countries together, and in a fixed effects setting, which includes countryspecific dummies (fixed effects), which thus allow for different population growth trajectories in each of the ENPCs included in the analysis. At a second stage, the analysis is replicated for each ENPC separately in order to examine the stability of the region-wide results across countries and to produce country-specific evidence of the impact that agglomeration has on growth. Table 3 reports the results from the region-wide analyses, and Table 4 summarizes the country-specific results.

As can be seen in the first column of Table 3, the relation between agglomeration (population density) and regional growth (in population terms) across the entire ENPCs macroregion is statistically significant (at the $1 \%$ level) and consistent with the evidence of convergence: Increasing a region's population density by $1 \%$ point reduces the predicted annual growth rate by almost $0.3 \%$ points. In other words, more sparsely populated regions are found to have been growing faster during the period, and thus catching-up in terms of their population density with the higher agglomeration regions. The overall fit of the regression, however, is very small (adj. $R^{2}$ of 0.07 ). Adding country-specific fixed effects (so as to account for country-specific trends in population growth) to this specification increases the fit of the regression substantially (adj. $R^{2}$ of 0.43 ) but affects little the estimated elasticity of the agglomeration variable. Nevertheless, as is shown in the remainder of Table 3, this result is not homogeneous across the ENPCs sub-groups. In the ENPCs South sub-group (columns 3 and 5), the evidence of convergence is maintained and, indeed, somewhat strengthened, with the coefficient of the population density variable rising to around $-0.35 \%$. In contrast, in the ENPCs East sub-group (columns 4 and 6) the elasticity of growth to agglomeration becomes positive and remains, as before, highly significant statistically (at the $1 \%$ level). Quite clearly, in these countries the evidence points to (statistically) strong centripetal forces that lead to regional divergence-with high-density regions experiencing faster population growth and thus further strengthening of their agglomeration. As before, the result is consistent irrespective of whether country-specific fixed effects are included or not.

This finding is of particular interest, and it is consistent with debates elsewhere in the ENP literature (Whitman and Wolff 2010; Fritz-Vannahme and Schöler 2015, inter alia) about the heterogeneity of the EU neighborhood. Specifically, the results reported in Table 3 point to two very different trajectories in relation to the operation of agglomeration forces in the two ENPCs sub-groups, with cumulative causation type of effects dominating in the ENPCs East but a clear evidence of convergence in the ENPCs South. Although we have no way of testing empirically the causes underlying these different trajectories, it should be noted that these are consistent with the general view in the literature, which suggests that countries that are in closer economic and political association with the EU (as is typical for the ENPCs East sub-group) tend to experience a widening of regional disparities partly as a result of the cumulative 


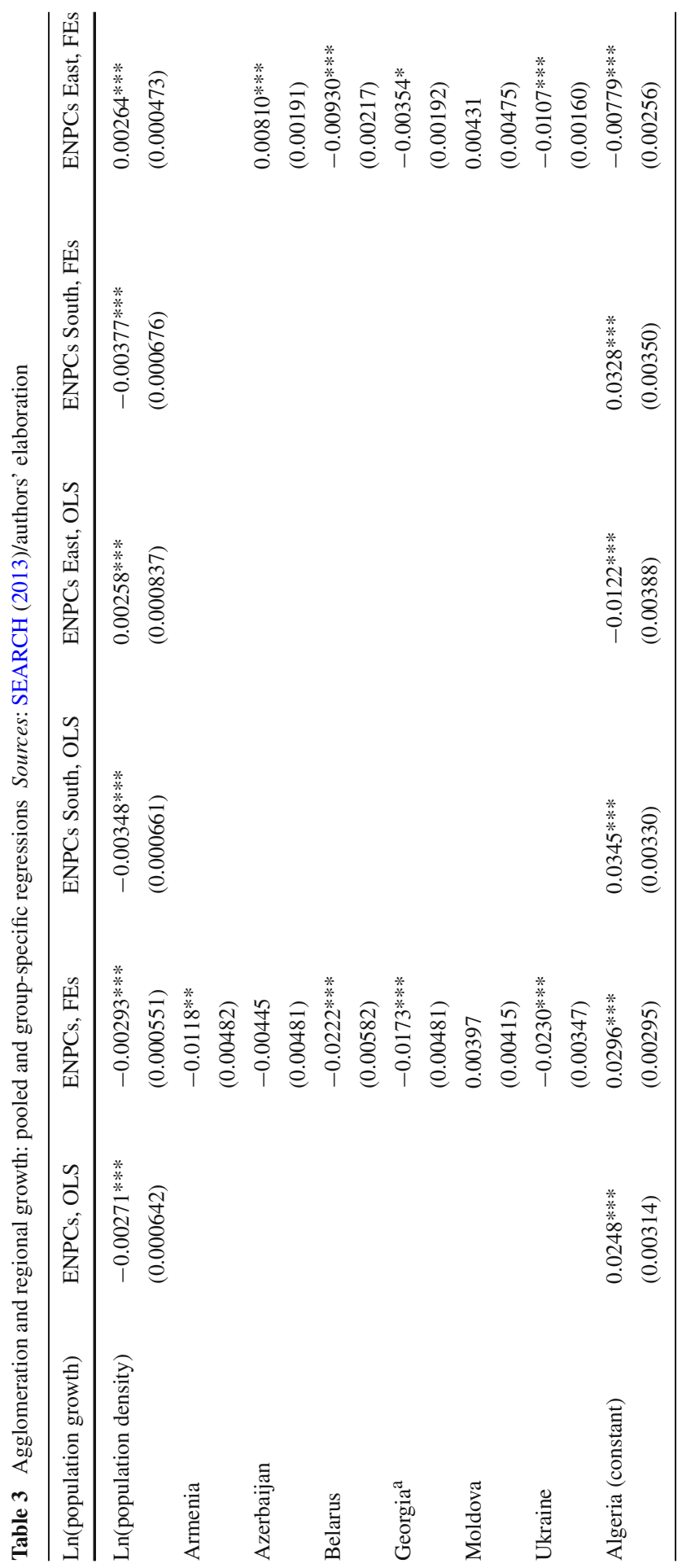




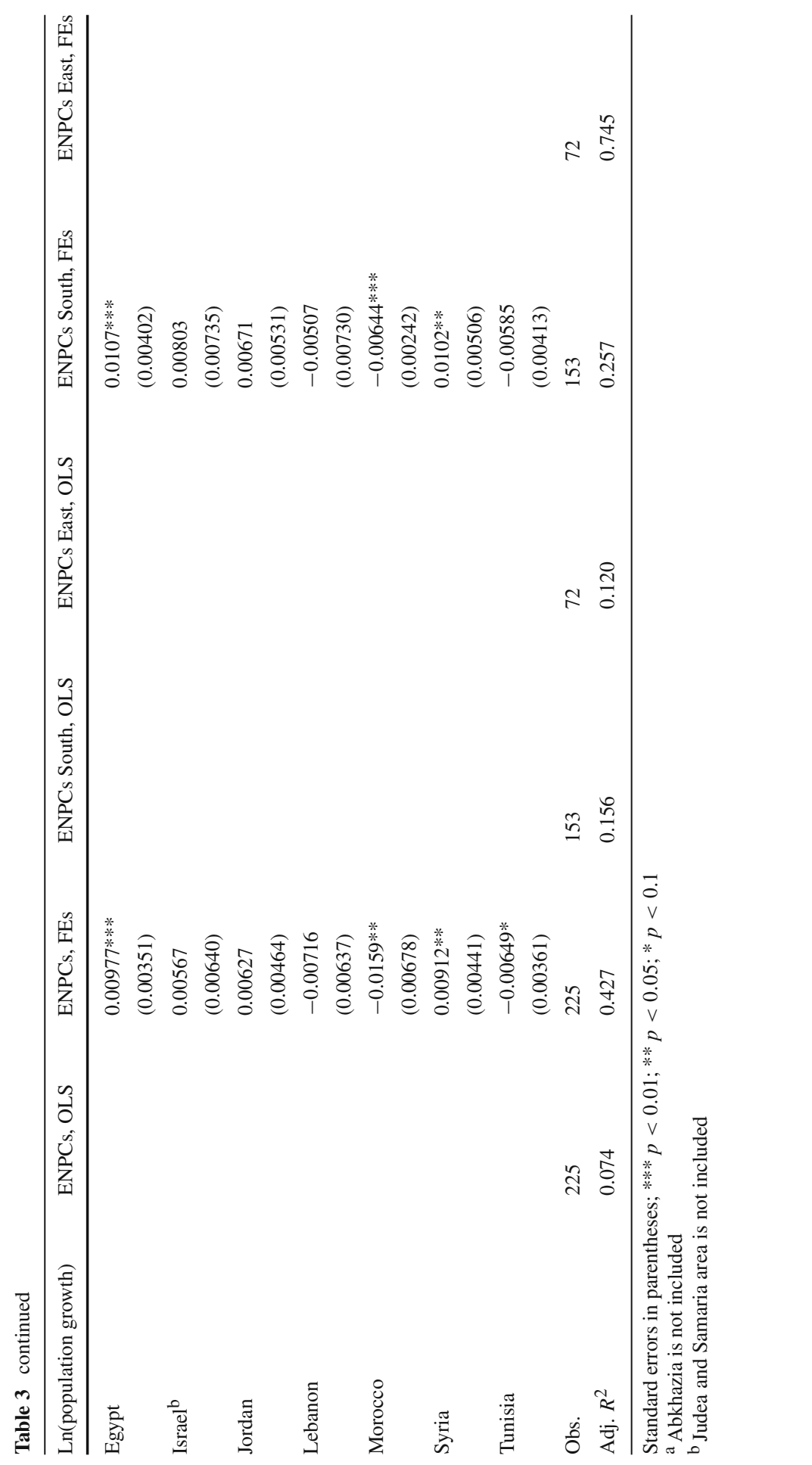


Table 4 Agglomeration and regional growth: country-specific regressions Sources: SEARCH (2013)/authors' elaboration

\begin{tabular}{|c|c|c|c|c|}
\hline Ln(population growth) & Constant & Ln(population density) & Obs. & Adj. $R^{2}$ \\
\hline Armenia & 0.000158 & 0.000916 & 11 & 0.036 \\
\hline$(2000-2011)$ & $(0.00759)$ & $(0.00158)$ & & \\
\hline Azerbaijan & 0.00693 & 0.00116 & 11 & 0.040 \\
\hline (2000-2012) & $(0.00863)$ & $(0.00190)$ & & \\
\hline Georgia $^{a}$ & $-0.0149 * *$ & $0.00350 * * *$ & 11 & 0.542 \\
\hline (2002-2012) & $(0.00474)$ & $(0.00107)$ & & \\
\hline Ukraine & $-0.0222 * * *$ & $0.00347 * * *$ & 27 & 0.463 \\
\hline$(2000-2012)$ & $(0.00342)$ & $(0.000747)$ & & \\
\hline Algeria & $0.0311^{* * *}$ & $-0.00330 * * *$ & 48 & 0.510 \\
\hline (1998-2008) & $(0.00211)$ & $(0.000477)$ & & \\
\hline Egypt & $0.0395^{* * *}$ & $-0.00295 * * *$ & 27 & 0.287 \\
\hline (1996-2012) & $(0.00514)$ & $(0.000931)$ & & \\
\hline Jordan & $0.0240 * * *$ & -0.000190 & 11 & 0.106 \\
\hline (2000-2011) & $(0.000807)$ & $(0.000174)$ & & \\
\hline Morocco & 0.0987 & $-0.0183^{* * *}$ & 16 & 0.453 \\
\hline (2003-2009) & $(0.0245)$ & $(0.00538)$ & & \\
\hline Syria & $0.0321 * * *$ & -0.00162 & 14 & 0.188 \\
\hline (2004-2011) & $(0.00512)$ & $(0.000971)$ & & \\
\hline Tunisia & -0.000114 & $0.00216^{* * *}$ & 24 & 0.203 \\
\hline (2004-2011) & $(0.00437)$ & $(0.000912)$ & & \\
\hline
\end{tabular}

Standard errors in parentheses; *** $p<0.01 ; * * p<0.05 ; * p<0.1$

a Abkhazia is not included

causation forces triggered by the "EU pull" (Kallioras and Petrakos 2010; Monastiriotis 2014; Monastiriotis et al. 2016, inter alia).

To examine further the validity of such an interpretation, and more generally to examine the stability of the above result across the different ENPCs, in Table 4 we present country-specific estimates of the model depicted by Eq. (1). Overall, the finding about a general differentiation between the ENPCs East and the ENPCs South subgroups holds also at the country level. In the ENPCs East sub-group, evidence of divergence is found in all cases, albeit this is statistically significant only in Georgia and Ukraine (in Armenia and Azerbaijan it fails the significance test at the $10 \%$ level). ${ }^{8}$ In contrast, in the ENPCs South sub-group, the obtained coefficients in all but one case

8 Evidence of divergence is also obtained for Belarus (significant at 1\%) and Moldova (not significant), but as these estimates are based on samples of less than 10 regions these results are not reported here. Similarly, in the ENPCs South sample we also get evidence of convergence additionally for Lebanon (significant at $5 \%$ ) and Israel (not significant), but these results are also excluded from Table 4. 
point to regional convergence: statistically significant in Algeria, Egypt and Morocco; ${ }^{9}$ statistically nonsignificant in Jordan and Syria; and only pointing toward divergence (significant at the 5\% level) in the case of Tunisia.

All in all, the findings reported in Tables 3 and 4 provide strong evidence that the role of agglomeration is very different in the two sub-groups of ENPCs. In the ENPCs East sub-group, there seems to be clear evidence of regional divergence or, as a corollary, evidence that agglomeration forces are in operation. Although the presence of a divergence dynamic may be seen as a negative trend for the countries concerned, it should also be noted that the evidence of significant positive agglomeration effects implies that these countries have stronger conditions for national growth as the cumulative strengthening of agglomerations naturally allows for a greater productivity potential to be realized. In contrast, in most of the ENPCs South sub-group, agglomerations seem not to be characterized by cumulative forces: although this leads to evidence of regional convergence (in population sizes), it is also a sign of weakness with regard to the forces that can stimulate productivity and growth at the national level. The implication is that these economies may be in a trajectory that affords them a lowering of spatial disparities (regional convergence) but within a context of weakening preconditions for national growth and, thus, catch-up convergence supra-nationally.

\section{Population growth and club formation}

Moving on to the econometric investigation for the emergence of regional convergence clubs, a couple of remarks have to be made first. The specification depicted in Eq. (3) endangers the possibility of considerable multicollinearity between the various powers of the independent variable, which in turn makes difficult the choice of the best parsimonious estimation. For this reason, the final selection on the specification of the equations was made under the rule of dropping the statistically nonsignificant terms and - in cases when two or more equations had statistically significant coefficientswith respect to the (lowest) AIC (Akaike 1973). All equations have been estimated in an OLS setting, providing for heteroskedasticity-consistent standard errors (White 1980). The results from this analysis ${ }^{10}$ are presented in Table 5 and visualized in Fig. 1. ${ }^{11}$

As can be seen, the convergence clubs analysis points to a consolidated spatial pattern in the vast majority of ENPCs (i.e., relative stability in spatial differences over time). Statistically, evidence of club formation (in that the nonlinear terms of the ini-

\footnotetext{
9 Peridy et al. (2013) find no evidence of (conditional) convergence in Morocco and Egypt. Given that our specification and data, as well as units of analysis, differ quite substantially to those of Peridy et al. (2013), it is not appropriate to make a direct comparison of the results of the two studies. We note, however, that the difference in results, and in their policy implications, points to the need for more work to be done on the topic-a direction in which we hope this paper contributes to.

10 Belarus, Moldova, Lebanon and Israel are excluded from Table 5 due to small regional samples.

11 As discussed previously, convergence clubs equations suffer, by nature, from high level of multicollinearity (cf. Table A2 in the supplemental data online for the presentation of the Variance Inflation Factors). Yet, so long as the underlying specifications are correct, the high level of multicollinearity does not actually bias results. The problem is that, in case of high level multicollinearity, when the coefficients of the convergence clubs models are used for prediction purposes, large errors may produce (Chatterjeeet al. 2000).
} 
Table 5 Gap persistence and club formation Sources: SEARCH (2013)/authors' elaboration

\begin{tabular}{|c|c|c|c|c|c|}
\hline Final gap & Initial gap $\wedge 1$ & Initial gap $\wedge 2$ & Initial gap $\wedge 3$ & Obs. & Adj. $R^{2}$ \\
\hline $\begin{array}{l}\text { Armenia } \\
(2000-2011)\end{array}$ & $\begin{array}{l}1.014675 * * * \\
(0.00579)\end{array}$ & & & 11 & 0.997325 \\
\hline $\begin{array}{l}\text { Azerbaijan } \\
(2000-2012)\end{array}$ & $\begin{array}{l}1.007762 * * * \\
(0.006425)\end{array}$ & & & 11 & 0.995367 \\
\hline $\begin{array}{l}\text { Georgia }^{a} \\
(2002-2012)\end{array}$ & $\begin{array}{l}1.003146 * * * \\
(0.009736)\end{array}$ & $\begin{array}{l}0.015041 * \\
(0.007045)\end{array}$ & & 11 & 0.999171 \\
\hline $\begin{array}{l}\text { Ukraine } \\
(2000-2012)\end{array}$ & $\begin{array}{l}1.042690 * * * \\
(0.002092)\end{array}$ & & & 27 & 0.998136 \\
\hline $\begin{array}{l}\text { Algeria } \\
(1998-2008)\end{array}$ & $\begin{array}{l}1.017018 * * * \\
(0.005967)\end{array}$ & $\begin{array}{l}-0.010443^{* * *} \\
(0.002507)\end{array}$ & & 48 & 0.988972 \\
\hline $\begin{array}{l}\text { Egypt } \\
(1996-2012)\end{array}$ & $\begin{array}{l}1.117227 * * * \\
(0.049427)\end{array}$ & $\begin{array}{l}-0.120831^{* *} \\
(0.047984)\end{array}$ & $\begin{array}{l}0.022210 * * \\
(0.009764)\end{array}$ & 27 & 0.993948 \\
\hline $\begin{array}{l}\text { Jordan } \\
(2000-2011)\end{array}$ & $\begin{array}{l}0.998263 * * * \\
(0.001695)\end{array}$ & & & 11 & 0.999963 \\
\hline $\begin{array}{l}\text { Morocco } \\
(2003-2009)\end{array}$ & $\begin{array}{l}0.874294 * * * \\
(0.066989)\end{array}$ & $\begin{array}{l}0.149776 * * \\
(0.064792)\end{array}$ & $\begin{array}{l}-0.043058^{* * *} \\
(0.013012)\end{array}$ & 16 & 0.996601 \\
\hline $\begin{array}{l}\text { Syria } \\
(2004-2011)\end{array}$ & $\begin{array}{l}0.988829 * * * \\
(0.002109)\end{array}$ & & & 14 & 0.999440 \\
\hline $\begin{array}{l}\text { Tunisia } \\
(2004-2011)\end{array}$ & $\begin{array}{l}0.863722 * * * \\
(0.026521)\end{array}$ & $\begin{array}{l}0.121867 * * * \\
(0.027571)\end{array}$ & $\begin{array}{l}-0.026816^{* * * *} \\
(0.006735)\end{array}$ & 24 & 0.999696 \\
\hline
\end{tabular}

Standard errors in parentheses; *** $p<0.01 ; * * p<0.05 ; * p<0.1$

a Abkhazia is not included

tial gap are statistically significant) is found for half of the ENPCs considered in the analysis (Georgia, Algeria, Egypt, Morocco and Tunisia); while for the remaining five countries we find evidence of universal convergence or divergence (i.e., a linear-only relationship). In Armenia, Azerbaijan and Ukraine we find that all regions diverge from the lead region (i.e., the final gap, in population density terms, is slightly higher as compared to the respective gap in the initial year) without converging toward an equilibrium gap level (there is no positive intersection of the fitted line with the benchmark $45^{\circ}$ line) and thus divergence is consistent throughout the sample. However, consistent with what we found in the analysis of the previous sub-section, only in Ukraine is the estimated coefficient statistically different from one (and, in terms of Fig. 1, only there does the fitted line deviate sufficiently from the $45^{\circ}$ line) and thus only there is the relationship one of divergence, rather than stability, in a statistical sense. Similarly, in Jordan and Syria the evidence points toward universal converge (the fitted line is below the $45^{\circ}$ line), but the difference is not statistically significant. Again, this is fully consistent with the findings of the previous sub-section. Finally, in the case of Georgia, although a nonlinear relationship is found, the evidence is again pointing to universal divergence - consistent with what was found in the previous sub-section and fully in line with the evidence obtained for the other ENP East countries. This is 
ENPCS that do not form regional convergence clubs (linear and non-inflection models)

Armenia

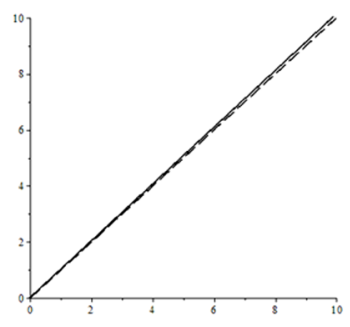

Fited line --45 line

Syria

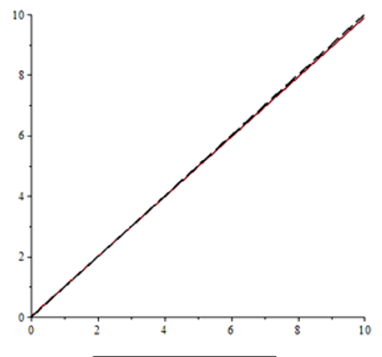

- Fitted line --45 hine
Azerbaijan

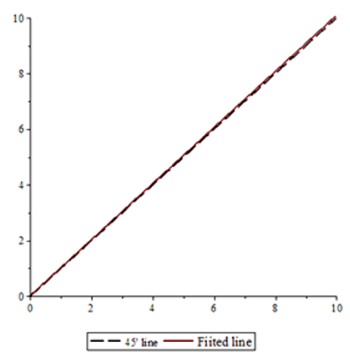

Ukraine

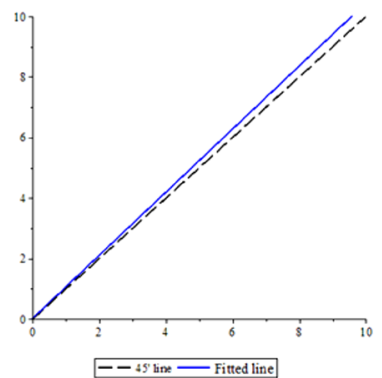

Jordan

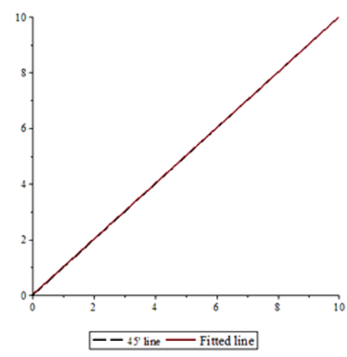

Georgia

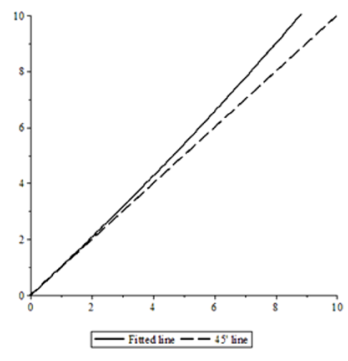

ENPCs that may form regional convergence clubs (non-linear models with inflection points)

\section{Algeria}

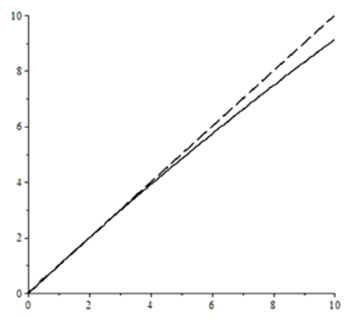

Fitted line $--45^{\prime}$ line

Morocco

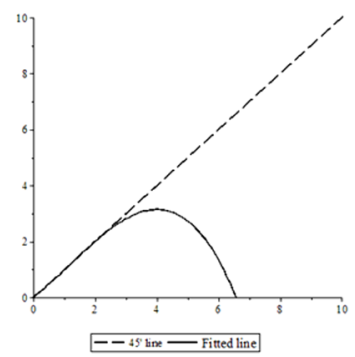

Abkhazia is not included.
Egypt

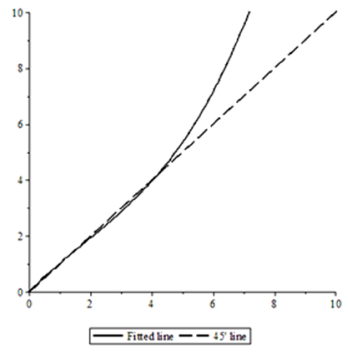

Tunisia

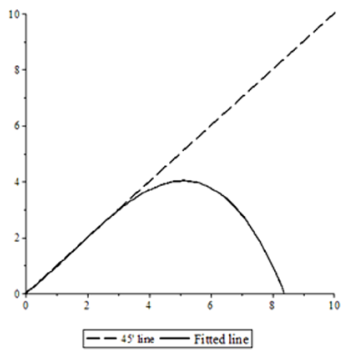

Fig. 1 Convergence clubs regression results. Sources SEARCH (2013)/Authors' elaboration 
because there is no positive intersection between the fitted line and the $45^{\circ}$ line (the quadratic term is positive and the linear term is above one), implying that all regions are diverge both from the lead region and from one another.

For the remaining four countries, all belonging to the ENPCs South, the relationship between initial and end-of-period gap is not only nonlinear but also produces an intersection point with the $45^{\circ}$ line. This means that in a statistical sense there is evidence of club formation. In Algeria, 26 out of the 48 regions are found to diverge from the lead region and to converge internally toward a club-specific equilibrium given by the intersection between the fitted and benchmark lines (this corresponds at an initial gap of 1.629). Notably, this club includes all coastal regions of the country. In turn, the remaining 21 regions, ${ }^{12}$ which are all landlocked, are also found to converge to the same equilibrium (at the aforementioned intersection) and, because of that, also to be moving closer (converge) to the lead region. This means that all regions in Algeria, with the exception of the lead region (Alger), converge within a single club; while the lead region diverges, forming a club of its own. The large membership of the convergence club explains the finding from the aggregate analysis of the previous sub-section, where the evidence was in favor of convergence; but the analysis of this sub-section shows that this pattern of convergence does not apply to the lead region, which follows its own divergent path. An analogous picture is found for Egypt. In this case, 16 out of the 27 regions appear to diverge from the lead region (the linear term is above the value of one) and to converge toward a club-specific equilibrium (as the quadratic term is negative, producing an intersection with the $45^{\circ}$ line) that corresponds to an initial gap of 1.263 . The remaining 10 regions $^{13}$ also converge to that point and thus are also part of this large convergence club-although for them the distance from the lead region is also reduced. Again, this is consistent with, but also sheds more light to, the evidence of universal convergence found in the aggregate analysis of the previous sub-section.

The cases of Morocco and Tunisia are different as here there are at least some regions that converge with the "lead" convergence club. In Morocco, which also returned evidence of convergence in our earlier analysis, the "lead" convergence club contains four additional regions ${ }^{14}$ besides the lead region of Grand Casablanca. As all regions in this club are coastal, it seems possible that the population growth dynamics observed there may be at least to some extent related to their geography. A set of eight regions diverges from this lead region club and converges internally to an equilibrium that corresponds to an initial gap of 2.063. Convergence to the same equilibrium characterizes the remaining 3 regions. ${ }^{15}$ These are all border regions, which had the highest initial gaps and thus their movement is convergent additionally to the "lead" club. In the case

\footnotetext{
12 These regions are: Mila, O. E. Bouaghi, S. B. Abbes, Msila, Saida, Tebessa, Tiaret, Khenchela, Biskra, Langhouat, Djelfa, El Oued, Naama, Ghardaia, El Bayadh, Ouargla, Bechar, Adrar, Tamanrasset, Tindouf and Illizi.

13 These regions are: Ismalia, Luxor, Menia, Suez, Aswan, North Sinai, South Sinai, Red Sea, Matrouh and El Wadi El Gidid.

14 These regions are: Rabat-Salé-Zemmour-Zaer, Gharb-Chrarda-Béni Hssen, Tanger-Tétouan, and Doukkala-Abda.

15 These regions are: Oriental, Guelmim-Es-Semara, and Oued Ed-Dahab-Lagouira.
} 
of Tunisia, the second convergence club, at an intersection point corresponding to an initial gap of 2.558 , contains only three (landlocked) regions. ${ }^{16}$ The remaining regions converge jointly to the lead region, forming a large convergence club (21 out of 24 regions nationally). In this case, the result appears much different from that obtained in our previous analysis, where we found strong evidence of divergence across the sample. It should be noted, however, that despite the fact that these results are econometrically strong (i.e., the nonlinear terms are statistically significant even at the $1 \%$ level), as can be seen in Fig. 1 the evidence of club formation is not particularly strong in economic terms: The distance of the fitted regression lines from the corresponding benchmark $45^{\circ}$ lines is hardly distinguishable in practically all cases (at least for in-sample values).

Overall, then, the results from the club convergence analysis help us shed more light to the patterns of convergence and divergence unveiled in the analysis of the previous sub-section, but they do not alter the obtained picture fundamentally. In a number of cases, we find evidence of divergence (for Ukraine, Armenia, Azerbaijan and Georgia) or convergence (for Jordan and Syria) from the lead region which is consistent with, and adds to, the overall pattern of divergence or convergence found in the aggregate analysis. In other cases (Algeria and Egypt), the aggregate evidence of convergence masks a force of separation (divergence) between the lead region and the rest of the country; while in two other cases convergence to the lead region is strong, but there is also a second club that is formed, which converges internally but diverges from the club of the lead region. It thus appears that the simple story that emerged from our earlier analysis - about a broader pattern of agglomeration-driven divergence in the ENPCs East and of weak agglomeration effects and convergence in the ENPCs South-is only part of the picture of the regional evolutions and dynamics in the ENPCs macroregion. We discuss the implications of this finding in the concluding section.

\section{Conclusions and policy implications}

Given that the EU experience has shown that deeper association may coincide with increasing spatial imbalances in growth performance levels, operating under "neighborhood Europeanization" conditions raises a salient issue with respect to the spatial pattern of growth in the ENPCs. Moreover, the recent turmoil and instability characterizing parts of the region raises also questions about (social and) spatial cohesion in these countries and thus about the extent of spatial imbalances there and of the recent dynamics characterizing such imbalances. With these considerations in the background, in this paper we analyzed the spatial population dynamics generated in the ENPCs, putting special emphasis on agglomeration forces and on the dynamic between population density and population growth, in particular.

Starting from a simple model of agglomeration and growth, we documented an aggregate relationship of convergence whereby low-density regions experience on the whole faster population growth. Underneath this aggregate pattern, however, we found

16 These regions are: Tozeur (which moves away from the "lead" club) and Kebili and TaTaouine (which move closer to the lead region). 
clear evidence that the role of agglomeration is markedly different in the two main sub-groups of the ENPCs macroregion. In the ENPCs, East sub-group agglomeration forces are in operation, leading to regional divergence; whereas in the ENPCs South sub-group agglomeration seems not to be characterized by cumulative forces. Still, in both cases, significant disparities in agglomeration exist, in the form of-sometimes huge_-differentials in population densities across metropolitan and more peripheral regions. The existence of such disparities poses a question concerning (their impact on) the evolution of spatial patterns of growth in the ENPCs. As the ENPCs become more associated with the EU structures and more open (politically and economically), the (new) pressures that may emerge may concentrate disproportionately the generation of growth in regions with conducive characteristics, such as high levels of population density (i.e., agglomeration forces), thus leading to further regional divergence also in the ENPCs South, similar to what is currently observed for the ENPCs East.

Taking this analysis further, we also examined the within-country stability of these patterns, by investigating empirically the presence of convergence clubs in relation to the growth trajectories of the leading agglomerations (most densely populated regions) in each of the countries covered by our analysis. Employing the method of convergence clubs, we found evidence of an unbalanced spatial pattern of growth, in population density terms, at least for a sub-set of the ENPCs. In the countries belonging to the ENPCs East sub-group, a clear trend of divergence was detected also in relation to their national lead region; in the ENPCs South sub-group, in contrast, convergence trends were typically more complex, with various instances of club formation coexisting with aggregate patterns of convergence (e.g., in Morocco) and divergence (e.g., in Tunisia).

Given that the ENPCs are not fully developed and are, typically, characterized by nonexistent or poorly-designed and under-funded regional policies, these spatial dynamics and imbalances may be an issue of serious concern in the immediate and medium-term future. Arguably, the reported results cover a specific period of substantial change in the ENP region, which may have nevertheless been put on a significantly different path, for at least a subset of these countries, following the developments that have followed the Arab Spring (e.g., in countries like Egypt and Syria) and the Ukrainian 2014 revolution. In this sense, we cannot claim that our results show longrun dynamics and prospects that apply today equally as they did in the first decade of the century. However, even if the patterns we reveal may be seen as temporary and/or specific to the period for which the analysis is performed, they are nevertheless indicative at least of some underlying tendencies that may persist, or reappear, in the future.

With this caveat in mind, our results would seem to call—at least for those parts of the ENPCs macroregion for which clear and multifaceted evidence of divergence was found-for a set of comprehensive, well-targeted and carefully-designed policy interventions, including on behalf of the EU, that would seek to enhance the economic potential of lagging-behind regions in the EU periphery and in this way help these regions to maximize the gains that they can derive from the prospective further integration of their countries with the EU. On the other hand, the derived evidence of centrifugal (convergence) tendencies can also be seen as a sign of the benign functioning of agglomeration forces, which can act as a trigger for national growth in a process of economic catch-up with the EU core - the benefits of which could potentially trickle 
down to the less developed and less populous regions in the future. In this sense, the policy challenge for the national and European policy-makers may be a short-term equity-efficiency trade-off, whereby providing support for lagging-behind regions in the immediate-run may compromise concurrent attempts to enhancing national growth. Our analysis, it is hoped, has helped identify the spatial growth context under which this policy challenge may be taken up in the future.

Acknowledgements The research was supported by the Project "Sharing KnowledgEAssets: InteRregionallyCohesive NeigHborhoods" (SEARCH) within the 7th European Community Framework Programme FP7-SSH-2010.2.2-1 (266834) European Commission. We would like to thank the editor and the referees for their constructive comments and suggestions.

Open Access This article is distributed under the terms of the Creative Commons Attribution 4.0 International License (http://creativecommons.org/licenses/by/4.0/), which permits unrestricted use, distribution, and reproduction in any medium, provided you give appropriate credit to the original author(s) and the source, provide a link to the Creative Commons license, and indicate if changes were made.

\section{References}

Ades AF, Glaeser EL (1995) Trade and circuses: explaining urban giants. Q J Econ 110:195-227

Akaike H (1973) Information theory and an extension of the maximum likelihood principle. In: Petrov BN, Csaki F (eds) Second international symposium on information theory. Akademiai Klado, Budapest, pp 267-281

Baldwin RE, Martin P (2004) Agglomeration and regional growth. In: Henderson VJ, Thisse J-F (eds) Handbook of regional and urban economics vol 4: cities and geography. Elsevier, Amsterdam, pp 2671-2711

Barrios S, Strobl E (2009) The dynamics of regional inequalities. Reg Sci Urban Econ 39(5):575-591

Beenstock M, Felsenstein D (2008) Regional heterogeneity, conditional convergence and regional inequality. Reg Stud 42(4):475-488

Beeson P (1987) Total factor productivity growth and agglomeration economies in manufacturing, 19591973. J Reg Sci 27(2):183-199

Berry B (1961) City size distributions and economic development. Econ Dev Cult Change 9:573-588

Boschma R, Minondo A, Navarro M (2012) Related variety and regional growth in Spain. Pap Reg Sci 91(2):241-256

Braunerhjelm P, Borgman B (2004) Geographical concentration, entrepreneurship and regional growth: evidence from regional data in Sweden, 1975-1999. Reg Stud 38(8):929-947

Brülhart M, Sbergami F (2009) Agglomeration and growth: cross-country evidence. J Urban Econ 65(1):4863

Chatterjee S, Hadi AS, Price B (2000) Regression analysis by example, 3rd edn. Wiley, New York

Chatterji M (1992) Convergence clubs and endogenous growth. Oxf Rev Econ Policy 8:57-69

Chatterji M, Dewhurst JHL (1996) Convergence clubs and relative economic performance in Great Britain: 1977-1991. Reg Stud 30:31-40

Cheshire P, Magrini S (2000) Endogenous processes in European regional growth: convergence and policy. Growth Change 31(4):455-479

Coombes P (2000) Marshall-Arrow-Romer externalities and city growth. CERAS Working Paper 99-06

Crescenzi R, Rodriguez-Pose A, Storper M (2007) The territorial dynamics of innovation: a Europe-United States comparative analysis. J Econ Geogr 7:673-709

Dall Mitze T, Schmidt T (2015) Internal migration, regional labor markets and the role of agglomeration economies. Ann Reg Sci 55:61-101

Demchuck P, Zelenyuk V (2009) Testing differences in efficiency of regions within a country: the case of Ukraine. J Product Anal 32:81-102

Duranton G, Puga D (2001) Nursery cities: Urban diversity, process innovation, and the life cycle of products. Am Econ Rev 91(5):1454-1477 
Duranton G, Puga D (2014) The growth of cities. In: Aghion P, Durlauf SN (eds) Handbook of economic growth, vol 2. Elsevier, Amsterdam, pp 781-853

EC (2004) European neighborhood policy strategy paper COM 373 FINAL. Commission of the European Communities, Brussels

EC (2010) Taking stock of the European neighborhood policy COM 207 FINAL. Commission of the European Communities, Brussels

EC (2011) A new response to a changing neighborhood: a review of European Neighborhood Policy COM 303 FINAL. Commission of the European Communities, Brussels

EC (2015) Review of the European Neighborhood Policy, joint communication to the European parliament, the council, the European economic and social committee and the committee of the region. European Commission, Brussels

El-Shakhs S (1972) Development, primacy and systems of cities. J Dev Areas 7:11-35

Fritz-Vannahme J, Schöler G (2015) The EU neighborhood in shambles: some recommendations for a new European neighborhood strategy. Bertelsmann Stiftung, Gütersloh

Fujita M (1988) A monopolistic competition model of spatial agglomeration: a differentiated product approach. Reg Sci Urban Econ 18(1):87-124

Galor O, Weil D (2000) Population, technology and growth: from the Malthusian regime to the demographic transition and beyond. Am Econ Rev 90:806-828

Glaeser EL (1999) Learning in cities. J Urban Econ 46(2):254-277

Glaeser EL, Scheinkman JA, Shleifer A (1995) Economic growth in a cross-section of cities. J Monet Econ 36:117-143

Glaeser EL, Kallal HD, Scheinkman JA, Shleifer A (1991) Growth in cities. NBER Working Paper 3787

Hansen G, Prescott EC (2002) Malthus to Solow. Am Econ Rev 92:1205-1217

Harris JR, Todaro MP (1970) Migration, unemployment and development: a two-sector analysis. Am Econ Rev 60:126-142

Henderson JV (2002) Urbanization in developing countries. World Bank Res Obs 17(1):89-112

Henderson JV, Wang HG (2005) Aspects of the rural-urban transformation of countries. J Econ Geogr $5: 23-42$

Heslsey RW, Strange WC (1990) Matching and agglomeration economies in a system of cities. Reg Sci Urban Econ 20(2):189-212

Kallioras D, Petrakos G (2010) Industrial growth, economic integration and structural change: evidence from the EU new member-states regions. Ann Reg Sci 45:667-680

Kallioras D, Tsiapa M (2015) The regional dimension of economic growth in Ukraine. East Eur Bus Econ J 1(3):71-95

Kokko A, Kravtsova V (2012) Regional characteristics and effects of inward FDI: the case of Ukraine. Organ Mark Emerg Econ 3(2/6):91-118

Lipshitz G, Raveh A (1998) Socio-economic differences among localities: a new method of multivariate analysis. Reg Stud 32(8):747-757

Lucas RE (1988) On the mechanics of economic development. J Monet Econ 22:3-42

Lucas RE (2004) Life earnings and rural-urban migration. J Polit Econ 112(S1):S29-S59

Monastiriotis V (2014) Regional growth and national development: transition in Central and Eastern Europe and the regional Kuznets curve in the East and the West. Spat Econ Anal 9(2):142-161

Monastiriotis V, Borrell M (2013) Origin of FDI and domestic productivity spillovers: does European FDIs have a "productivity advantage" in the ENP countries?. SEARCH Working Paper 2/13

Monastiriotis V, Kallioras D, Petrakos G (2016) The regional impact of the European Union association agreements: an event-analysis approach to the case of Central and Eastern Europe. Reg Stud. doi:10. 1080/00343404.2016.1198472

Neven DJ (1995) Regional convergence in the European Union. J Common Mar Stud 33:47-65

Parr J (1985) A note on the size distribution of cities over time. J Urban Econ 18:100-112

Petrakos G, Brada JC (1989) Metropolitan concentration in developing countries. Kyklos 42(4):557-578

Petrakos G, Kallioras D, Anagnostou A (2011) Regional convergence and growth in Europe: understanding patterns and determinants. Eur Urban Reg Stud 18(4):375-391

Petrakos G, Tsiapa M, Kallioras D (2016) Regional inequalities in the ENP countries: the effects of growth and integration. Environ Plan C: Gov Policy 34:698-716

Peridy N, Hazem M, Brunetto M (2013) Some new insights into real convergence in MENA countries' regional areas: a spatial econometric analysis. Econ Bus Lett 2(4):150-160 
Portnov B, Erell E (2004) Interregional inequalities in Israel, 1948-1995: divergence or convergence? Socio-Econ Plan Sci 38:255-289

Quah D (1993) Empirical cross-section dynamics in economic growth. Eur Econ Rev 37:426-434

Quah D (1996) Regional convergence clusters across Europe. Eur Econ Rev 40:951-958

Rodriguez-Pose A, Fratesi U (2004) Unbalanced development strategies and the lack of regional convergence in the European Union. Reg Stud 38(1):97-113

SEARCH (2013) SEARCH Database. http://www.ub.edu/searchproject/ (retrieved December 2015)

Sveikauskas L (1975) The productivity of cities. Q J Econ 89(3):393-413

Wheaton W, Shishido H (1981) Urban concentration, agglomeration economies and the level of economic development. Econ Dev Cult Change 30:17-30

White H (1980) A heteroskedasticity-consistent covariance matrix and a direct test for heteroskedasticity. Econometrica 48:817-838

Whitman RGG, Wolff S (2010) The European Neighborhood Policy in perspective: context, implementation and impact. Palgrave Macmillan, Basingstoke 